\title{
Updating Probabilistic Seismic Intensity at Kathmandu after 2015 Gorkha Earthquake
}

\author{
Hari Ram Parajuli \\ Department of Civil Engineering, Pulchowk Campus, Tribhuwan University, Kathmandu, Nepal
}

\begin{abstract}
Subduction of Indian plate beneath the Eurasian plate has formed three thrust faults along Himalayas. Due to continuous shortening, many earthquakes have occurred in the past causing massive deaths and destructions showing that earthquakes are the greatest threat. Seismic hazard of the central Himalayan region has been examined based upon kernel density function method. Faults are so nearer that it is difficult to judge which earthquake belongs to which fault and even some parts of the faults do not hold earthquakes, and usual method of assigning the earthquakes to the nearest fault developing magnitude-frequency relationship is not applicable. Thus, seismic hazard is estimated considering area sources with different densities at each location based upon historical earthquakes using kernel density functions which account both earthquake sizes and numbers. Fault is considered as one earthquake with its highest magnitude at centre when calculating density but does not aid in earthquake data base for recurrence relationship. Since there are no specific attenuation laws developed for the Himalayan region, five attenuation laws developed for other subduction zones are selected and used giving equal weight to all to minimize the uncertainties. Then, probabilistic spectra for various natural periods at Kathmandu are calculated and plotted.
\end{abstract}

Key words: Earthquakes, faults, Himalayas, kernel density, seismic hazard, probabilistic spectra, 2015 Gorkha earthquake.

\section{Introduction}

Himalayas, the youngest mountain range, approximately 2,200 km in length, extends from north India through Nepal, Bhutan to eastern India. It was formed due to convergence of Indian plate and Eurasian plate millions years ago. Mountain building process is still ongoing because Indian plate is moving towards Eurasian plate [1]. The slip rate is approximately $2 \mathrm{~cm}$ per year. It means that in every 100 years Indian plate is plunging $200 \mathrm{~cm}$ beneath the Eurasia plate. High level of tectonic activity between the plates built present geology of Himalayas and three great faulting systems-HFT (Himalayan frontal thrust), MBT (main boundary thrust) and MCT (main central thrust) longitudinally through Nepal and STDT (South Tibetan detachment system) in the Tibetan region. The colliding force builds up pressure

Corresponding author: Hari Ram Parajuli, Ph.D., associate professor, research fields: earthquake engineering, structural engineering, lifeline risk management. continually for several years and this pressure is released in the form of earthquakes. Due to this process, the Himalayan arc has experienced great earthquakes. Three major earthquakes in 1505, 1833 and 1934 have been recorded in the Nepal Himalayan region in its history. Recently in 2015 a major quake M7.8 hits central Nepal claiming 8,900 peoples and damages one million houses. Damage distribution is shown in Fig. 1. Another very big earthquake has been revealed recently that is supposed to have occurred in the eastern Nepal though its exact location is yet to verify [2]. It shows that earthquakes are the greatest risk to the Himalayan region. Of the total length, Nepal itself holds approximately 1,000 km length of the central Himalayas. The seismic hazard assessment here is presented for this region.

As mentioned above, there are three faults systems in Nepal and another faulting system is in Tibetan regions. The conventional method used to estimate hazard is to develop recurrence relationship for each fault separately assigning the past earthquakes to the 


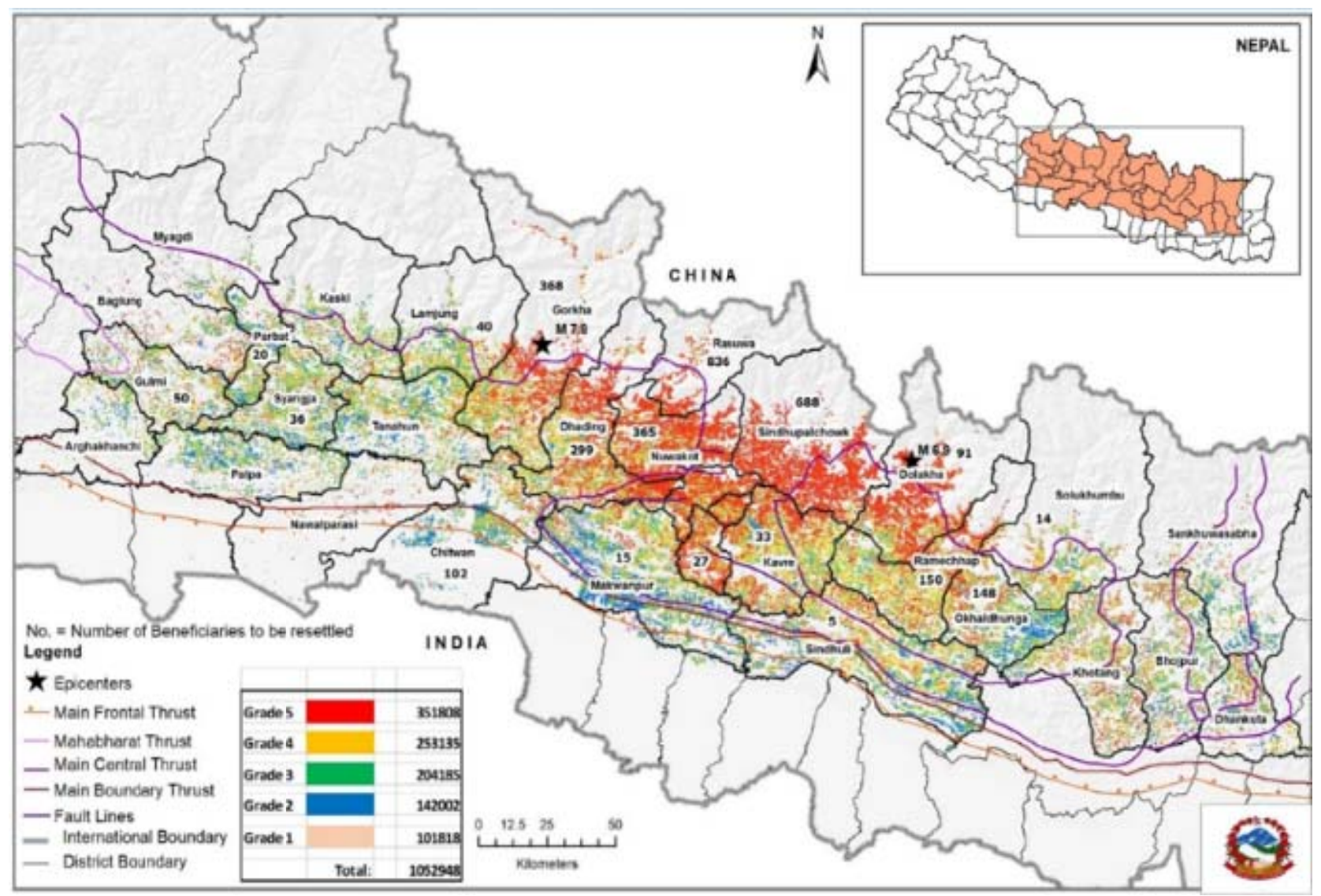

Fig. 1 Damages in 2015 Gorkha earthquake.

nearest faults. Here faults are so closed and it is very difficult to know which earthquake belongs to which fault. So, in this study, area sources are considered. The area is further subdivided into number of small areas call cells. All cells are taken as sources and separate recurrence relationship for all cells are developed considering all the earthquakes around $300 \mathrm{~km}$ radius from the centre of the cells. But, due to this assumption, there is possibility of smearing out of earthquake densities all over the areas. It over allocates earthquake densities over the areas where earthquakes have rarely occurred and under allocates earthquakes over the areas where earthquakes have occurred frequently. To overcome this discrepancy, separate density at each sub area is calculated based upon the numbers of earthquakes and their sizes at the cell and nearby cells by using kernel density method which is explained in the following sections.

\section{Recurrence Relationship}

Of the 2,200 km length of Himalayas, 1,000 km length of the Nepal Himalayas is divided into small grids at 0.5 and 1 degrees interval in latitude and longitude respectively. Then all the earthquakes within $300 \mathrm{~km}$ radius of each grid intersection (site) are collected. The earthquakes and the small digitized faults of that region are plotted in Fig. 2. The earthquake catalogue was formed merging the data from U.S. Geological Survey [4], Ambraseys and Jackson [5], Pant [6], BECA [7] and Ambraseys and Douglas [8]. The earthquakes data have been reported in different magnitudes and in intensity scales. To make uniformity, all data were converted to the moment magnitude [9] using various relationships given in McGuire [10] and scaling relationship for Himalayan region [8]. 


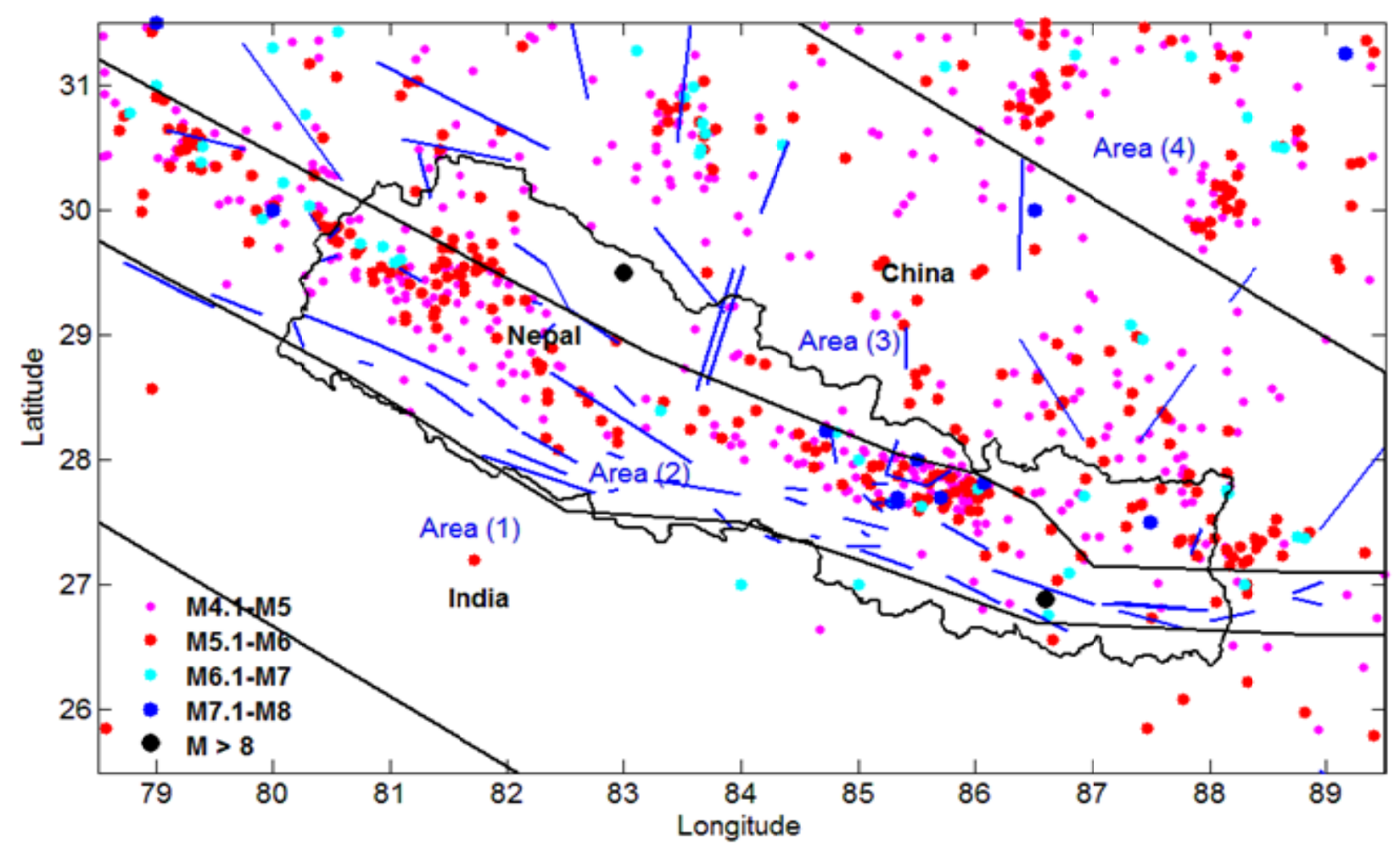

Fig. 2 Earthquakes in Himalayan region.

Following completeness method [11], magnitude frequency relationship is developed for each grid intersection separately. The coefficients ( $a$ and $b$ ) for frequency magnitude relation are obtained. The coefficient $a$ represents for numbers of earthquakes and $b$ value represents for rate of occurrence of bigger earthquakes. $a$ value is low for the southern sites and continuously increasing towards north. In an average $b$ value is 1 for the region. Maximum magnitude $\left(M_{\max }\right)$ reported in the data base is the highest magnitude of earthquake obtained from the catalogue.

\section{Attenuation Laws}

Because of unavailability of sufficient data, instead of developing new equation for the region, attenuation equations among already developed equations for subduction zone [12-20] which support the tectonics, geology and faulting system are studied. Out of them, considering five equations [15-20], attenuation laws that represent typical seismic environment are selected. Among them, Atkinson and Boore [17] predict the lowest values and Zhao et al. [20] the highest values. There is no certainty that future earthquakes obey any particular attenuation law. Thus, seismic hazard is estimated considering all attenuation giving equal weight.

\section{Probabilistic Spectra}

For each site, $600 \mathrm{~km} \times 600 \mathrm{~km}$ area is taken as source and divided into smaller sub-areas (cells) of 10 $\mathrm{km} \times 10 \mathrm{~km}$ size. Distances between centre of cells and site are calculated. Only the cells within $300 \mathrm{~km}$ radius are considered to make the recurrence equation applicable. The mean rate in Eq. (1) of exceeding particular value of acceleration is calculated by summing up all the probabilities of occurrences of earthquakes given magnitudes and distances.

$$
v_{y^{*}}=\sum_{i=1}^{N_{s}} v_{i_{M \min }} \iint P\left[Y>y^{*} \mid m, r\right] f_{M i}(m) f_{R i}(r) d m d r
$$

where, Ns is number of sources in the region, $v_{i_{M \min }}=\exp \left(\alpha_{i}-\beta_{i} m_{\min }\right)$ is total rate of exceedances of threshold magnitude ( $M=5.0$ is taken in this study), 
with $\alpha=2.303 \mathrm{a}, \quad \beta=2$ 2.303b. $P\left[Y>y^{*} \mid m, r\right]$ is conditional probability that is chosen acceleration exceeded for a given magnitude $(M)$ and distance $(R)$, and $f_{M i}(m)$ and $f_{R i}(r)$ are probability density functions for magnitude and distance respectively. Here, $M$ and $m$ are used as random variable and specific value for magnitude respectively. The probability density function for Gunterberg-Richter law with lower and upper bound magnitudes is expressed in Eq. (2).

$$
f_{M}(m)=\frac{\beta \exp \left[-\beta\left(m-m_{\min }\right)\right]}{1-\exp \left[-\beta\left(m_{\max }-m_{\min }\right)\right]}
$$

Earthquake density is simply number of earthquakes per unit area. However, size of earthquake makes major influence in terms of effects. Effect of a single big event would be far greater than thousands of smaller events. Thus, activity rate based upon size of earthquake is calculated using kernel estimation method [21]. Considering total rate around the particular site is unity, fraction of activity rate which called earthquake density here, for all the sources around the site is calculated depending upon the numbers and size of the earthquakes available in and nearby cells. The mean activity rate $\lambda(m, x)$, at a cell is taken as a kernel estimation sum considering the contribution of $N$ events inversely weighted by its effective return period which satisfies the condition (Eq. (3)) that can be obtained from Eqs. (4)-(7).

$$
\begin{gathered}
r \leq h\left(m_{j}\right) \\
\lambda(m, x)_{i}=\sum_{j=1}^{N} \frac{K\left(m_{j}, r_{j}\right)}{T\left(r_{j}\right)} \\
K(m, r)_{j}=\left[\frac{D}{2 \pi h\left(m_{j}\right)}\right]\left\{\frac{h\left(m_{j}\right)}{r_{j}}\right\}^{2-D} \\
h\left(m_{j}\right)=H \exp \left(C m_{j}\right) \\
\rho_{i}=\frac{\lambda(m, x)_{i}}{\sum_{i=1}^{N_{s}} \lambda(m, x)_{i}}
\end{gathered}
$$

where, $K(m, x)$ is kernel function, $T(r)$ is return period of the event located at distance from $r, h(m)$ is kernel band width scaling parameter shorter for smaller magnitude and vice vice-versa, which may be regarded as a fault length [22] and $D$ is fractal dimension which is taken as 1.7. $H$ and $C$ are constants equal to 1.45 and 0.64 . Magnitude is divided into $0.1 \mathrm{M}$ and distance into $10 \mathrm{~km}$ intervals. $N_{m}$ and $N_{r}$ are the total numbers of magnitude and distance bins.

There are many small faults around the big faults systems (Fig. 3a). Earthquakes have occurred in or near some of the faults but many of them are empty. Even if the faults have earthquakes, they are not sufficient to develop magnitude frequency relationship. Thus, areal sources have been taken as explained above. However, these faults are also real evidences of historical seismicity, even though there might not be any earthquakes with in the short time span. So, one equivalent earthquake with its maximum magnitude [23] was assigned at each fault. Then earthquake densities by using kernel method are calculated and plotted for historical earthquakes (Fig. 3b) and faults (Fig. 3c). Higher densities can be seen where greater earthquakes and big faults exist. Future earthquake may occur near the fault or near the location of past earthquakes, outside also.

There is no certainty where future quakes occur. Thus, to account this uncertainty, average of both is taken and multiplied to Eq. (1) yields Eq. (8) which gives mean rate of occurrences at a particular site.

$$
\begin{gathered}
v_{y^{*}}=\sum_{i=1}^{N_{s}} \sum_{j=1}^{N_{r}} \sum_{k=1}^{N_{m}} v_{i_{M \min }} \rho_{i} P\left[Y>y^{*} \mid m, r\right] P[M= \\
m] P[R=r] \Delta m \Delta r
\end{gathered}
$$

Mean rate of exceedances for peak ground accelerations and various spectral accelerations are calculated from five attenuation laws. Considering earthquake occurrences follow Poisson's process, accelerations for three probabilities of exceedances in 50 years were calculated from all attenuation laws at each site, and combined together giving equal weights. PGA (peak ground acceleration) and SA (spectral accelerations) at various natural periods for $10 \%$ 


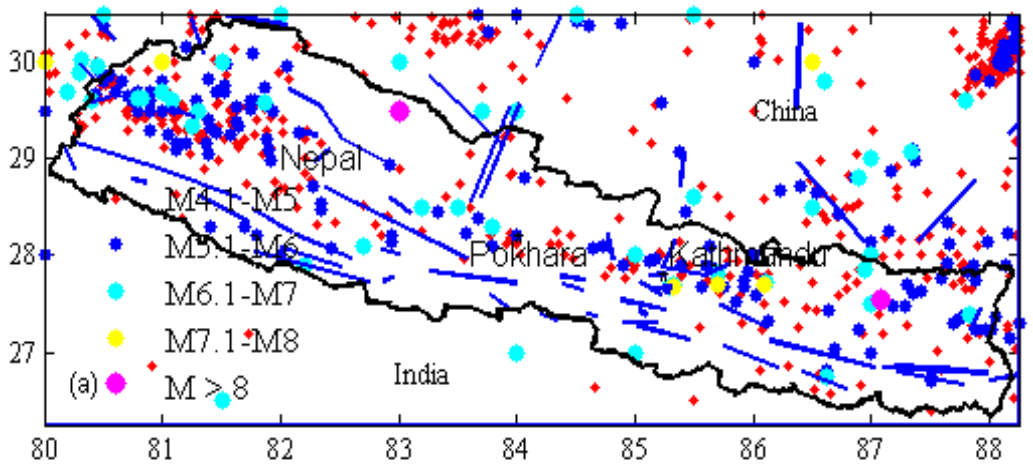

(a)

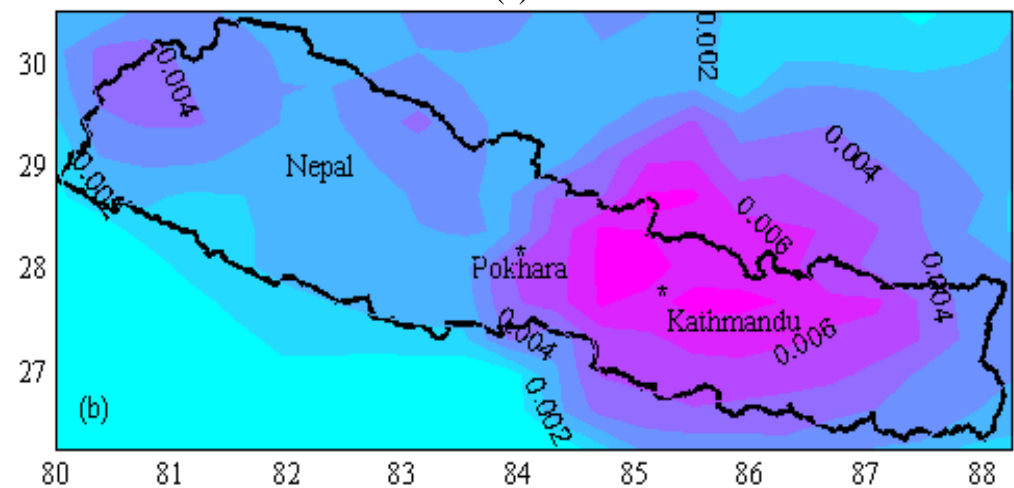

(b)

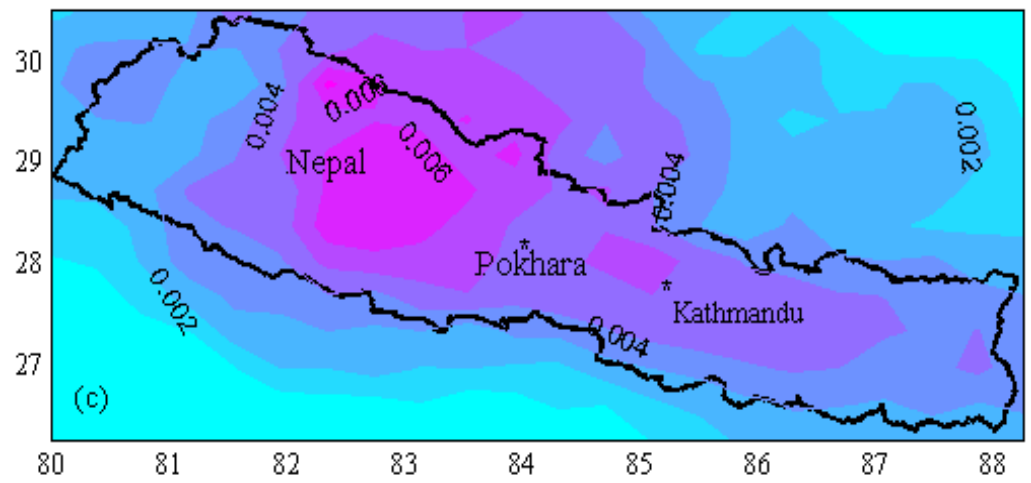

(c)

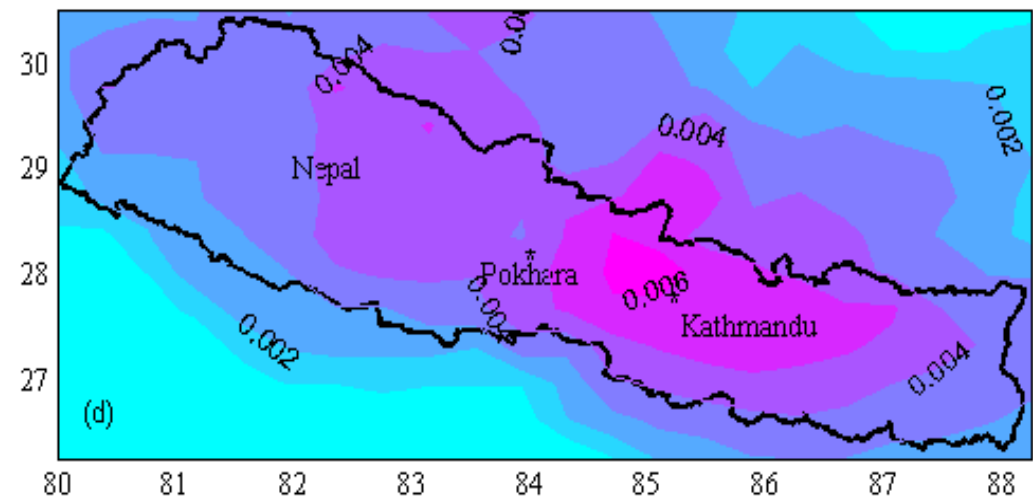

(d)

Fig. 3 (a) Historical earthquakes and faults; (b) Densities from historical earthquakes; (c) Densities from faults; (d) Combined density from earthquakes and faults. 


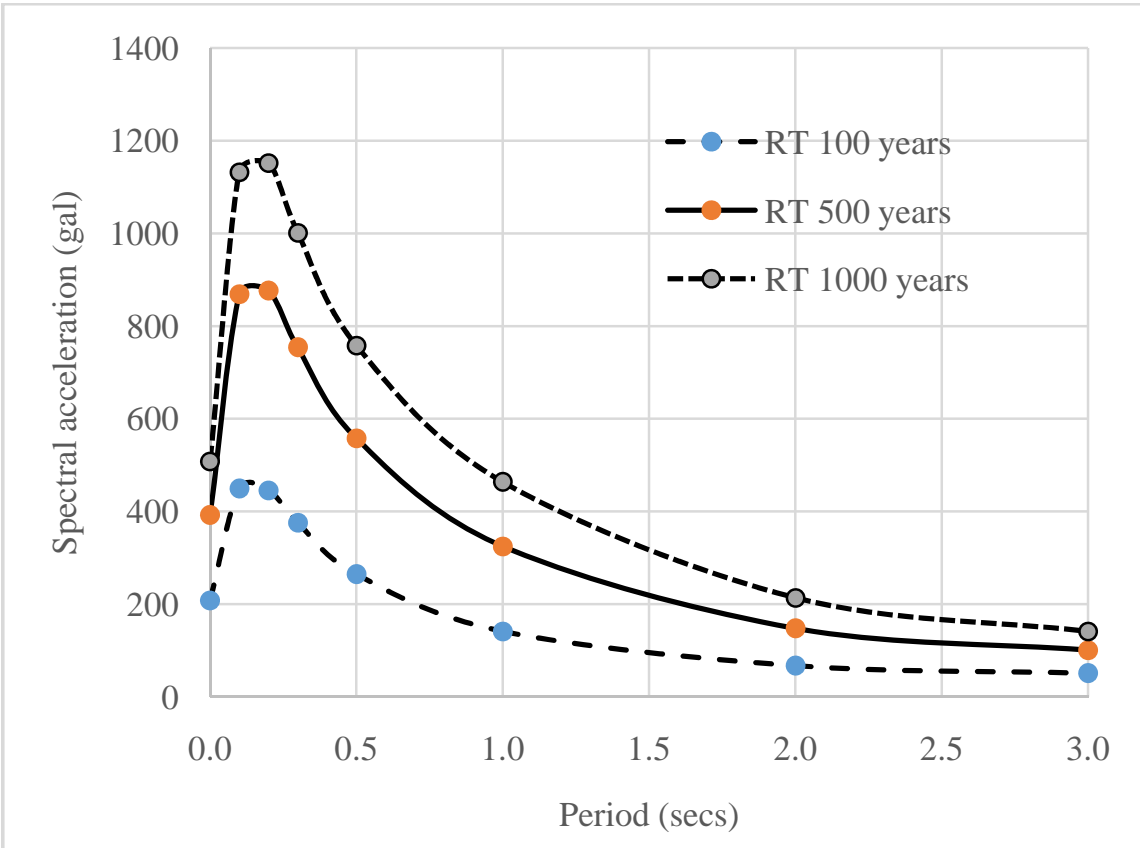

Fig. 4 Probabilistic spectra at Kathmandu (rock).

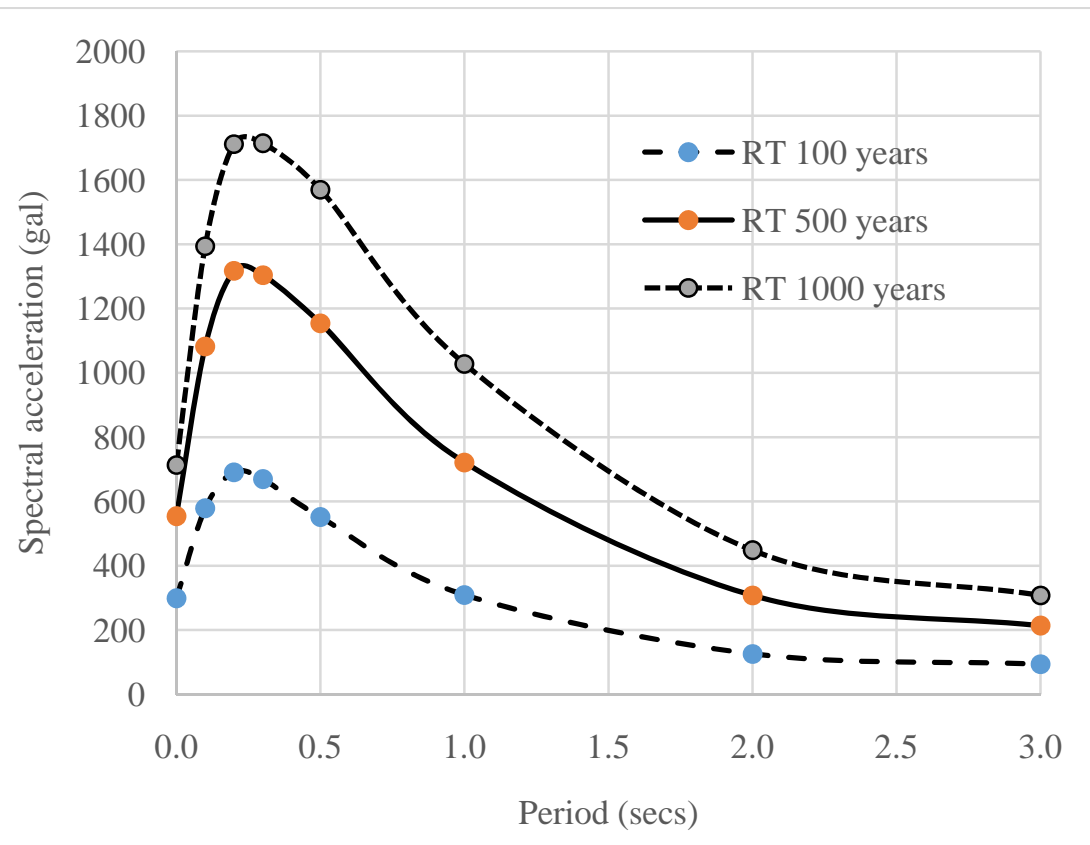

Fig. 5 Probabilistic spectra at Kathmandu (soil).

Table 1 Acceleration at rock and soil condition.

\begin{tabular}{|c|c|c|c|}
\hline \multirow{2}{*}{ Return period } & \multicolumn{2}{|c|}{ Peak ground acceleration (gal) at } & \multirow{2}{*}{-Amplification factor } \\
\hline & Rock & Soil & \\
\hline 100 & 208 & 298 & 1.435 \\
\hline 475 & 392 & 554 & 1.412 \\
\hline 975 & 508 & 714 & 1.404 \\
\hline Average & & & 1.417 \\
\hline
\end{tabular}


probabilities of exceedances in 50 years (475 years return period) for hard soil condition for $5 \%$ damping are calculated and plotted (Fig. 3). Obtained probabilistic spectra for Kathmandu, the city of Himalayan region are shown in Fig. 5.

\section{Conclusion}

Mean rate of exceedances for peak ground accelerations and various spectral accelerations are calculated from seven attenuation laws. Considering earthquake occurrences follow Poisson's process, accelerations for three probabilities of exceedances in 50 years were calculated from all attenuation laws at each site, and combined together giving equal weights. Peak ground acceleration for 100, 475 and 975 years are found 298, 554 and 714 gals respectively. Other values in various natural periods are plotted as shown in Figs. 4 and 5. It is the case for hard soil. Kathmandu has very soft soil and ground motion can be easily amplified reaching higher values approximately 1.417 (Table 1). Thus, for particularly at Kathmandu, spectra have been plotted in Figs. 4 and 5.

The values are quite high and higher than previous estimate [7] also. Thus, the previous estimate should be revised to better estimate the seismic hazard for the purpose of building code.

\section{References}

[1] Molnar, P. 1984. "Structures and Tectonics of Himalaya: Constraints and Implication of Geophysical Data.” Ann. Rev. Earth Planet Sci. I2: 489-518.

[2] Bilham, R., and Ambraseys, N. N. 2005. "Apparent Himlayan Slip Deficit from the Summation of Seismic Moments for Himalayan Earthquakes.” Current Science 88 (10): 1658-63.

[3] Bilham, R., Gaur, V. K., and Molnar, P. 2001. "Himalayan Seismic Hazard.” Science 293: 1442-4.

[4] USGS. http://earthquake.usgs.gov/earthquakes/eqarchives /epic/epic_rect.

[5] Ambraseys, N. N., and Jackson, D. 2003. "A Note on Early Earthquakes in Northern India and Southern Tibet.” Current Science 84 (4): 570-82.

[6] Pant, M. R. 2000. “A Step towards Historical Seismicity of Nepal.” Fransco-Nepal Conference on People,
Environment and Landscape of Himalayas, Nepal.

[7] BECA World International (New Zealand) in association with SILT Consultants (P.) Ltd. (Nepal), TAEC Consult (P.) Ltd. (Nepal), Golder Associates (Canada) and Urban Regional Research (USA). 1993. Seismic Hazard Mapping and Risk Assessment for Nepal.

[8] Ambraseys, N. N., and Douglas, J. 2004. "Magnitude Calibration of North Indian Earthquakes.” Geophysics. J. Int. 159: 165-206.

[9] Hank, T. C., and Kanamori, H. 1979. “A Moment Magnitude Scale.” Journal of Geophysics Res. 84: 2348-50.

[10] McGuire, R. K. 2004. "Seismic Hazard and Risk Analysis.” Earthquake Engineering Research Institute, MNO-10.

[11] Stepp, J. 1992. "Analysis of Completeness of the Earthquake Sample in the Pudet Sound Area and Its Effect on Statistical Estimates of Earthquake Hazard.” Proceedings of the First Microzonation Conference, 897-909.

[12] Crouse, C. B. 1991. "Ground-Motion Attenuation Equations for Earthquakes on the Cascadia Subduction Zone.” Earthquake Spectra 7 (2): 201-36.

[13] Fukushima, Y., and Tanaka, T. 1990. “A New Attenuation Relation for Peak Horizontal Acceleration of Strong Earthquake Ground Motion in Japan." Bulletin of Seismological Society of America 80 (4): 757-83.

[14] Molas, G. L., and Yamazaki, F. 1995. "Attenuation of Earthquake Ground Motion in Japan Including Deep Focus Events.” Bull. Seismol. Soc. Am. 85: 1343-58.

[15] Youngs, R. R., Chiou, S. J., Silva, W. J., and Humhrey, J. R. 1997. "Strong Ground Motion Attenuation Relationships for Subduction Zone Earthquakes.” Seismological Research Letters 68 (1): 58-73.

[16] Gregor, N. J., Silva, W. J., Wong, I. G., and Youngs, R. R. 2002. "Ground-Motion Attenuation Relationships for Cascadia Subduction Zone.” Bull. Seismol. Soc. Am. 92 (5): 1923-32.

[17] Atkinson, G. M., and Boore, D. M. 2003. "Empirical Ground-Motion Relations for Subduction-Zone Earthquakes and Their Application to Cascadia and Other Regions.” Bull. Seismol. Soc. Am. 93 (4): 1703-29.

[18] Atkinson, G. M., and Boore, D. M. 2008. "Erratum to Empirical Ground-Motion Relations for Subduction-Zone Earthquakes and Their Application to Cascadia and Other Regions. Bull. Seismol. Soc. Am. 98 (5): 2567-9.

[19] Kanno, T., Narita, A., Morikawa, N., Fujiwara H., and Fukushima, Y. 2006. "A New Attenuation Relation for Strong Ground Motion in Japan Based on Recorded Data.” Bull. Seismol. Soc. Am. 96 (3): 879-97.

[20] Zhao, J. X., Zhang, J., Asano, A., Ohno, Y., Oouchi, Y., Takahashi, T., Ogawa, H., Irikura, K., Thino, H. K., 
Somerville, P. G., Fukushima, Y., and Fukushima, Y. 2006. “Attenuation Relations of Strong Ground Motions in Japan Using Site Classification Based upon Predominant Period.” Bull. Seismol. Soc. Am. 96 (3): 898-913.

[21] Woo, W. 1996. "Kernel Estimation Methods for Seismic Hazard Area Source Modeling.” Bull. Seismol. Soc. Am. 86 (2): 353-62.
[22] Chen, Y., Liu, J., Chen, L., Chen, Q., and Chan, L. S. 1998. "Global Seismic Hazard Assessment Based on Area Source Model and Seismicity Data.” Natural Hazards, Kluwer Academic Publishers 17: 251-67.

[23] Wells, D. L., and Copersmith, K. J. 1994. "New Empirical Relationships among Magnitude, Rupture Length, Rupture Width, Rupture Area, and Surface Displacement.” Bull. Seismol. Soc. Am. 84 (4): 974-1002. 